\title{
Exploring a Fourth Space for Composition Studies Research
}

\author{
John R. Baker ${ }^{1} \&$ Patrick Bizzaro² \\ ${ }^{1}$ National Quemoy University, Taiwan. Email: drjohnbaker@yahoo.com \\ ${ }^{2}$ Professor Emeritus, East Carolina University, U.S.A. Email: pbpp@auxmail.iup.edu
}

\begin{abstract}
The research methods landscape has the potential to be quite diverse. However, the paradigmatic battles between the two empirical research camps (quantitative and qualitative) and the more recent embracement of mixed-methods research has narrowly focused many fields' attention, including that of composition studies, away from other sorts of useful methods, such as theoretical research. To address this, this sequential two-part study compares and contrasts the (a) purpose, (b) instruments, (c) data, and (d) structure of quantitative and qualitative research. Drawing on this four-part structure, this study advances composition studies research methods literature by posing and testing a definition of theoretical research through an examination of full-length core composition studies texts $(\mathrm{N}=12)$. The article concludes by explaining the study's relevance to the field and offering directions for future research.
\end{abstract}

Keywords: Theoretical Research, Composition Studies, Rhetoric

"When I use a word," Humpty Dumpty said in rather a scornful tone, "it means just what I choose it to mean-neither more nor less."

"That's a great deal to make one word mean," Alice said in a thoughtful tone.

“The question is," said Humpty Dumpty, "which is to be master-that's all."

—Through the Looking Glass, Alice Carroll

\section{Introduction}

As researchers in the field of composition, we can engage in several kinds of research. Our attention to such diversity, however, is often distracted by the thunderous clamor of the territorial battles raging between various research camps aspiring to garner our attention and emerge, as Humpty Dumpty says, master. In this paper, we (the authors) briefly reference a battle that has raged between the camps of one type of research-empirical research-to illustrate why this skirmish has drawn so much of our attention from the other regions of the research landscape. Then, via theoretical exemplification, we offer a definition and future direction for an often-overlooked kind of research, theoretical research.

To do so, we first compare and contrast the (a) purpose, (b) instruments, (c) data, and (d) structure of the two empirical research camps. Using these four criteria, we discuss the results of a sequential two-part study. In the first study, we, the authors, examine eight published texts purported to be, although not specifically designated as, theoretical research in the field of composition studies. From this analysis, we propose a working definition of theoretical research that incorporates the first and fourth criteria (purpose, structure), specifically that theoretical research is one where the author, hopefully ethically, surveys data via a sustained discussion that

(C) AesthetixMS 2020. This Open Access article is published under a Creative Commons Attribution Non-Commercial 4.0 International License (http://creativecommons.org/licenses/by-nc/4.0/), which permits non-commercial re-use, distribution, and reproduction in any medium, provided the original work is properly cited. For citation use the DOI. For commercial re-use, please contact editor@rupkatha.com. 
allows the reader to deductively or inductively come to a conclusion. We further demonstrate that the second and third criteria (instruments, data) are not exclusive to one type of research area, as the instruments and data employed in theoretical research can be found across types. We, then using replicability theory (Stube, 2000) test this definition in the second part by reporting the results of a second examination of four additional texts.

\subsection{Empirical Research (Quantitative and Qualitative)}

One area of the research landscape, empirical research, commands a great deal of attention, but this is not because it is the only kind of research there is. That would be, in Alice's words, "a great deal to make one word mean" (Carrol, 1872, p. ). Rather, empirical research commands such attention because one of its rising camps, qualitative research, has spent a great deal of powder railing against its quantitative elder in order to carve a cartographic place for itself on the research map (Vogt, 2008). In this territorial battle, supporters of qualitative research have attempted to define their camp and the camps of others via a contrastive descriptions of each camp's (a) purpose, (b) data, (c) instruments, and (d) structure (Brannen, 2017; Given, 2008; Silverman, 2016).

Using these definitional criteria, we can describe quantitative research, in its narrowest form, as aiming to investigate preidentified hypotheses using instruments that investigate a wide variety of data (including archival data) to produce statistical results (Fraenkel et al., 2012; Martin \& Bridgmon, 2012; ). An archetypal example of such a study might be Sherman's (1893) seminal work, where he examines a series of texts to demonstrate whether sentence length has historically shortened by era (i.e., from the pre-Elizabethan period to present). This sort of investigation results in a tightly controlled study where a hypothesis is posed (e.g., sentence length shortens by era), a set number of variables are investigated (e.g., sentence length and era), and the results are presented statistically. Such a study is then be presented in a rather compartmentalized structure to demonstrate the researcher's findings: (a) introduction (statement and significance of the problem) (b) review of the related literature, (c) methods (research questions, participants, settings, instruments), (d) data analysis, (e) summary, conclusions, and recommendations.

Qualitative research, on the other hand, is defined more broadly. It adopts a holistic approach of naturalistic observation to explore complex settings using non-numerical instruments (Miles \& Huberman, 1984). These instruments often include interviews, nonparticipant and participant observation, and autoethnography, but they may also include analyses of archival material. Revisiting the Sherman's study on sentence length, a qualitative study using archival analysis might involve having students read a set of texts from different eras and then interviewing them to determine what about the long sentences in these texts causes them trouble (e.g. matters of difficulty other than mere length) (Baker, 2020). With regards to structure, the format of such a qualitative research study would be different from that of quantitative research in that it would be presented in a less rigid format that employs thick description while eschewing statistical analysis (Geertz, 1973; Ponterotto, 2006). Nevertheless, this qualitative research, too, would be presented in a compartmentalized fashion to demonstrate what the researcher found (White et al., 2003).

Identifying the two camps in this way is uncomplicatedly convenient and brief. However, an examination of the actual work done in the field identifies a problem that arises when strict binaries are imposed (Johnson \& Onwuegbuzie, 2007). Following this sort of plan, tyrannical masters, for instance, might sketch polarized maps that detail their and their enemy's camps, but 
such exclusivity fairs poorly among the masses (Caruth, 2013; Lund, 2012). Like dutiful citizens, researchers may blindly recite the rhetoric of their autocratic quantitative and qualitative despots, but their day-to-day research behaviors show that they fail miserably at staying within demarcated lines. There are, of course, studies that have maintained the artificially defined armistice, but many researchers and their studies have noticeably migrated to a middle space, a third space, where noncombatants borrow from both camps as their needs direct to the point that the map has had to be redrawn. This space is commonly referred to as mixed methods (Cresswell \& Clark, 2017; Ghiara, 2020; Lund, 2012). To illustrate this middle ground, drawing on our example of era and sentence length again, a researcher might first employ quantitative analysis to determine whether the sentences in archival materials actually shorten by era. She might also employ quantitative analysis to determine whether the students' comprehension is affected via a standardized test or recall protocol. She would then conduct qualitative interviews to determine what contributed to this reduction in performance. Like quantitative and qualitative studies, this type of study would also be presented in a compartmentalized format to demonstrate to the reader what the researcher found.

\subsection{Nonempirical Research (Theoretical Research)}

The civil war between the empirical camps, as mentioned earlier, has created a great deal of disorientating noise to the point that it leaves many in a fog where they cannot imagine other possibilities. Lost in this confusion, proponents rotely tout the rhetoric of one camp or another and plod along, choosing research methods from one of the camps or a mix of the two.

As researchers, we, however, like Humpty Dumpty, have the prerogative to sit noninvolvedly upon the wall to survey, from a safe distance, the struggles between the tempirical camps, recognizing they are just that: struggles between empirical camps that are best left there. As self-professed noncombatants, we can therefore choose not to let the noise of the quantitativequalitative battle distract our attention from the very real research done in other areas on the methodological map.

Sitting safely upon the wall, turning our eyes from the fray, we can spy another region, a less embattled one. This region is that of nonempirical research, often called theoretical research. This sort of research, like the empirical camps, can be illustrated with a discussion of four criteria: (a) purpose, (b) instruments, (c) data, and (d) structure. While arguably not a new resident in the research field (Peritz, 1977), and one that has gained limited ground in many fields (Chu, 2015; Chu \& Ke, 2017; Thyer, 2010), this fourth space remains largely uncharted in composition studies. That is not to say that this method is entirely absent on the literary landscape. Instead, it is underused, and when it is employed, it is most often not identified as such.

\section{Current Exploration}

In the previous section, we explained that theoretical research, like empirical research (quantitative and qualitative), can be understood by examining its (a) purpose, (b) instruments, (c) data, and (d) structure. To illustrate this, we now present a sequential two-part study. In the first study, using the four criteria, we explored eight texts (six articles and two full-length books) that were presented to me as theoretical research. Drawing on this investigation, we proposed a definition of theoretical research. In the second study, we tested this definition through a further 
examination of four full-length books. After exploring these texts, we will pose a working definition of theoretical research.

\subsection{Study 1}

2.1.2 Methodology

Using the four criteria presented earlier (purpose, instruments, data, structure), we examined the eight texts listed in Table 1 to demonstrate that each was written for a similar purpose (to make an argument) and uses a similar structure (a sustained presentation of data) while maintaining some important differences with regards to instruments and data.

Table 1

Composition Texts Purported to be Theoretical Research

1. Berlin, J. (1987). Rhetoric and reality: writing instruction in American colleges, 1900-1985. Southern Illinois University Press.

2. Elbow, P. (1998). Writing without teachers. Oxford University Press.

3. Miller, S. (1992). Writing theory: Theory writing. In G. Kirsch, \& P. A. Sullivan (Eds.). Methods and methodology in composition research (pp. 15-36). Southern Illinois University Press.

4. Mutnick, D. (1998). Rethinking the personal narrative: Life-writing and composition pedagogy. In C. Farris, \& C. M. Anson (Eds.). Under construction: Working at the intersections of composition theory, research, and practice (pp. 79-92). Utah State University Press.

5. Ray, R. (1992). Composition from the teacher-research point of view. In G.

Kirsch \& P. A. Sullivan (Eds.) Methods and methodology in composition research (pp. 172-189). Southern Illinois University Press.

6. Sullivan, P. A. (1992) Feminism and methodology in composition studies. In G. Kirsch, \& P. A. Sullivan. (Eds.) Methods and methodology in composition research (pp. 15-36). Southern Illinois University Press.

7. Vandenberg, P. (1998). Composing composition studies: scholarly publication and the practice of discipline. In C. Farris, C., \& C. M. Anson (Eds). Under construction: Working at the intersections of composition theory, research, and practice (pp. 19-29). Utah State University Press.

8. Zebroski, J. (1998). Toward a theory of theory for composition studies. In C. Farris, \& C. M. Anson (Eds). Under construction: Working at the intersections 
of composition theory, research, and practice (pp. 30-50). Utah State University Press.

\subsubsection{Results}

The first two texts (Berlin, 1987; Elbow, 1987) examine the practical day-to-day concerns we compositionists deal with. Berlin (1987), in his text Rhetoric and Reality: Writing Instruction in American Colleges, 1900-1985, for example, guides the reader on an epistemic journey through a mountain of historical data in blocks of time from 1900 to 1975 and generalizations to 1985 . In this extended discussion, he gives readers the opportunity to engage this data to look past their Burkean terministic screens and "reevaluate many old assumptions about the teaching of writing" (p. 9): the power structures that bore it, house it, compete for it, and administrate it, as well as the process itself. The result is prompting readers to examine their belief systems and create more informed ones so that they might not fall prey to any work "claiming to be the one, true system" (p. 4), thus moving the field forward in healthy ways.

Elbow (1998), in Writing Without Teachers, presents his view of what this healthy progress looks like; that is, writing without teachers. To do this, he uses autoethnographic reflection to examine the history of his own struggles with writing. This sustained discussion gives readers an opportunity to examine and challenge their own beliefs about how one is to learn to write, both inside and outside the academy. During this reflection, Elbow also provides a sketch of how to develop and operate a course that can, if one accepts its fluid nature, have a place both inside and outside the academy.

The next three studies offer another option for forward movement: promoting social change (Miller, 1992; Mutnick, 1998; Sullivan, 1992). In the first article, Writing theory: Theory writing, Miller (1992) examines the history of composition, pointing readers toward what she considers to be a healthy future direction. Miller identifies four historical phases of composition studies and offers an extended review of literature relevant to the first three phases: (a) "a purely pragmatic phase, aimed at establishing the most effective teaching methods," (b) a "transitional phase that has described processes and constructed largely psychologistic models, using limited explanatory concepts," and (c) "a fully theoretical' time when theories are broadened to account for social activity and to include multidisciplinary perspectives" (p. 78). She then identifies a fourth "vital stage" where "whatever philosophical alliances we claim, we will as both writers and readers inevitably encounter postmodern fragmentations of discourse" (p. 8o).

In the second article, Sullivan (1992) also engages historical data to promote social change. Sullivan's sustained argument is more directed than Millers', focused on feminist methodology, and the data she draws on in her 1992 text Feminism and methodology in composition studies are fewer, as she argues there is fewer feminist data to cover. In her sustained discussion, she argues that there should be more of a feminist voice in composition studies. She does this by contrasting the marginalized place feminist theory and composition studies have historically held and thus argues that they should create a civil union in their common goals. She then argues, referencing a limited amount of archival data (a reflection on an article by Steven North and her own qualitative work), that this has yet to happen, but that it could.

Mutnick (1998) offers a third text for social change. In her article, Rethinking the personal narrative: Life-writing and composition pedagogy, she offers a sustained argument that student narratives can be used as sources of data to help both the writer and researcher better understand issues of class and race. To illustrate this, she uses a different sort of data. She reflects on the 
writing of one of her students, Dmitry, a Russian immigrant who comes to terms about "why he left his beloved city" in Russia; that is, to escape old "Soviet politics." She argues that this paper autoethnographically gave Dmitry the opportunity to reflect on his situation. She also argues that, as an artifact, Dmitry's paper provides data to help readers understand his situation and see how it might make it difficult for him to complete his studies. This type of writing stands in contrast to other forms of ethnography that are written by others to nostalgically preserve and reify the memory of an oral society but can ignore the Other's place in the dominant society.

Along another vein of purpose, the last three articles (Ray, 1998; Vandenberg, 1998; Zebroski, 1998) approach the subject of publishing itself. Vandenberg (1998), in his article Composing composition studies: scholarly publication and the practice of discipline, examines historical edicts as far back as 1883 to illustrate how a power relationship has emerged wherein those who publish about composition studies stand above those who practice it. Vandenberg concludes that the latter are complicit in perpetuating this evil by not publishing themselves.

Zebroski (1998) offers an examination of prior publications about the theory of composition studies. In this sustained discussion, she "rejects the assumption that theory informs practice by proposing a model of theorizing in which theory becomes one of several historically situated practices which develops only in a complex connection with signifying, teaching, curricular, and other practices" (p. 5). She does this to argue that "compositionists now must pursue their own kind of theory which arises from the grassroots of composition" (p. 32).

Ray (1998), in her work Composition from the teacher-research point of view, examines archival data (other studies) and employs personal reflection of her own research to argue for the value of empirical teacher research, a type of research that typically utilizes empirical methodology, both quantitative (e.g., surveys, questionnaires, discourse analyses of student texts) and qualitative (e.g., journal keeping, participant observation, and interviews).

\subsubsection{Conclusions and Discussion}

Having examined the above texts using the four features we proposed (purpose, instruments, data, structure), we now pose a working definition of theoretical research. In the eight texts and the first and fourth feature (purpose, structure), the authors, hopefully ethically, survey data via a sustained discussion (structure) that guided readers to deductively and/or inductively come to a conclusion (purpose). More specifically, two texts (Berlin, 1987; Elbow, 1987) examined the practical day-to-day concerns we compositionists deal with; three attempted to promote social change social change (Miller, 1992; Mutnick, 1998; Sullivan, 1992); and three approached the subject of publishing itself (Ray, 1998; Vandenberg, 1998; Zebroski, 1998).

Drawing on these data, the following working definition is supported:

Theoretical research is one where the author, hopefully ethically, surveys data via a sustained discussion where he guides readers to deductively and/or inductively come to a conclusion.

This definition cartographically separates theoretical research from the empirical camps (quantitative and qualitative). The structure (a sustained discussion) and purpose (to allow the reader to deductively and/or inductively come to a conclusion) are, for example, markedly different from those of the empirical camps. In the empirical camps, articles are more compartmentalized in order to demonstrate to the reader what was found, whereas theoretical research arguments are sustained to invite the reader into the argument. 
The other two criteria reviewed, instruments and data, however, do not appear to be exclusive to theoretical research. Six of the studies reviewed in this study employed historical data (Berlin, 1987; Miller, 1992; Ray, 1992; Sullivan, 1992; Vandenberg, 1998; Zebroski, 1998), but as illustrated by the era and sentence length example, historical data are not exclusive to theoretical research. Two of the studies also used a different sort of data. Elbow (1987), for example, employed autoethnographic reflection and Mutnick (1998) proposed student narratives, both of which have been used by the empirical camps.

\subsection{Study 2}

Study 1 resulted in a working definition of theoretical research via an examination of seven articles and one full-length book. To further test this definition, we, accepting the importance of replicability and generalizability theory (Strube, 2000) replicated the methodology used in Study 1 with a new data set.

\subsubsection{Methodology}

Using the four criteria presented earlier (purpose, instruments, data, structure), we tested the definition that emerged from Study 1, by examining four more full-length texts. These are listed in Table 2.

Table 2

Composition Texts Purported to be Theoretical Research

1. Donoghue, D. (2008). The last professors: The corporate university and the fate of the humanities. Fordham University Press.

2. Ede, L. S., \& Lunsford, A. A. (1990). Singular texts/plural authors: Perspectives on collaborative writing. Southern Illinois University Press.

3. Gee, J. P. (2007). Good video games + good learning: Collected essays on video games, learning, and literacy. Lang.

4. Peckham, I. (2010). Going north thinking west: The intersections of social class, critical thinking, and politicized writing instruction. Utah State University Press.

The first text, Gee's (2007) Good Video Games + Good Video Learning, is reminiscent of Berlin (1987) and Elbow (1987) in that it examines a practical day-to-day concern we as teachers deal with: in this case, how students learn. Specifically, Gee demonstrates that there is indeed a bridge between games and education that is both cognitively beneficial and should not be influenced by gender, race, and nationality. He further demonstrates that this boon is not necessarily available to everyone, such as those without economic access to such technology. Beginning with an autographic look at his son's and his own "learning and personal interaction 
with ... game[s]" (p. 47), Gee moves on to an in-depth look at data concerning games and their relation to education: games themselves, their accompanying materials, educational texts, and his own and other's previous work in theory. He also offers Dickenson poems and dialogues between parents and children. Drawing on this wide variety of data, he demonstrates that children need worlds that are meaningful and that are girded by the tenets of good pedagogy, "whether they be virtual, real, or a combination of the two" (p. 3). As he writes, "games are very good at getting themselves learned" (p. 2).

In the second text, Peckham (2010)—like Miller (1992), Mutnick (1998), and Sullivan, (1992) - discusses composition pedagogy and social change yet argues such critical pedagogy. Countering a colleague's claim that teachers should teach critical thinking, Peckham argues that "pedagogical approaches that promote social justice. . . ironically penalize working-class students" (p. 163), in that well-intentioned curricula, materials, and teachers act "against workingclass children in unintended ways" (p. 11). This is because the students do not end up learning how to write. He makes this argument by reflecting on his experiences with his working-class family and community, his work as a writing program administrator, his students, his research, others' research, and critiques of others' reflections on student writing.

The third text, Ede and Lundsford's (1990) Singular Texts/Plural Authors: Perspectives on Collaborative Writing, deals with publishing, much like Ray, (1998), Vandenberg (1998), and Zebroski (1998), although the authors, like Sullivan (1992), are also writing for feminism-inspired social change. Specifically, they guide the reader through a pastiche of data: (a) a reflection on a study that employed structured and semi-structured questionnaires of corporate authorship in seven fields, (b) brief case study narratives, (c) a Nietzschean presentation of text excerpts, and (d) a historical examination of texts (novels, work of other theorists, etc.). From there, the authors craftily narrow the discussion to a postmodern discourse on race, class, and gender. The text then moves onto to its intended focus: female writers' diminished place in corporate authorship.

The fourth text, Donoghue (2008) The last professors, moves in a new direction and explores the plight of the tenured professor. Donaghue explains that although tenure affords professors much-needed and valuable "time to research and write as well as teach" (p. xi), which in turn allows them the freedom to think and best serve their students, tenured professors face a bleak future. To make this argument, he examines a great number of historical events as far back as where universities first began. He then moves on to a point about 80 years ago when the idea of tenure first came about. From there, he continues toward recent historical events that are bringing the idea of tenure to a demise: vocational goals, online classes, online universities, rankings, and general bean counting.

\subsubsection{Study 2, Conclusions and Discussion}

By examining the four texts in light of their purpose and structure, we suggest that the authors (hopefully ethically) presented an argument in the form of a sustained discussion of data that guided readers to deductively and/or inductively come to a conclusion. One text illustrated the value of games in education (Gee, 2007). Two addressed social change, one addressed pedagogy designed to promote social change (Peckham, 2010), another argued for more of a feminist presence in corporate authorship (Ede \& Lundsford, 1990). The final text (Donoghue, 2008) illustrated the bleak future of the tenured professor.

The other two criteria employed in these studies (instruments, data), again, do not appear to be exclusive to theoretical research. Two of the studies, for example, incorporated 
autoethnographic reflection (Gee, 2007; Peckham, 2010); three drew on the authors' own research (Ede \& Lundsford, 1990; Gee, 2007; Peckham 2010); three drew on others' research (Gee's, 2007; Ede \& Lundsford, 1990; Peckham, 2010); two offered literary excerpts, either poems (Gee, 2007) or prose (Ede \& Lundsford, 1990); one included an exploration of parent-child conversation (Gee, 2007); one examined student texts (Peckham, 2010); and another employed an analysis of historical events (Donoghue's (2008).

Examining the results of Study 2 the definition of theoretical research presented in Study 1 is supported.

\section{Conclusions and Discussion}

Drawing on the two studies in this paper, the following definition of theoretical research is supported: Theoretical research is a type of research in which the author, hopefully ethically, surveys data via a sustained discussion that guides readers to deductively and/or inductively come to a conclusion. Unpacking this definition and addressing the two of the four criteria employed in this study (purpose and structure), we argue that theoretical research's purpose, in the most idealistic terms, is to, hopefully in an ethical way, offer a realistic view of things rather than reify our terministic screens (Berlin, 1992). To do this, we suggest that researchers, when clarifying their methods, conduct a wide survey of data, and when doing so, they should endeavor to allow truth to form not by holding too tightly to any one view or preconceived hypothesis but instead by letting truth ethically synthesize (Connors, 1992). When presenting this data, they should do so in a sustained argument that lets readers discover the truth along the way or in one that nudgingly guides the reader to a conclusion. This less compartmentalized sort of structure than that of empirical research because the researcher must, instead of presenting the paper in the compartmentalized fashions used by quantitative and qualitative research, present the data in the form of a sustained argument that invites the reader to use deductive and inductive reasoning to come to a conclusion.

Revisiting the example about sentence length throughout historical eras, a theoretical research study might include an examination of historical documents that prescriptively or descriptively outline what sentence length best facilitates reading comprehension. This, in turn, would guide and invite readers to draw conclusions about how sentence length can and should be considered as a factor in reading comprehension.

We argue, however, that instruments and data are not defining factors of theoretical research. The examination of articles and books presented in this article demonstrates that theoretical research uses a wide variety of instruments and data, including some that are also employed in empirical research.

\section{Suggestions for Further Study}

This paper has advanced composition studies research methods literature by moving beyond the empirical research paradigmatic discussions (Ghiara, 2020; Johnson \& Onwuegbuzie, 2007; Lund, 2012). Specifically, it has advanced research methods guides (Cresswell \& Clark, 2017; Fraenkel et al., 2011; Given, 2008; Martin \& Bridgmon, 2012; Miles \& Huberman, 1984) and literature (Chu, 2014; Chu \& Ke, 2017) toward a fourth space for composition studies by illustrating and offering a definition of theoretical research, albeit a preliminary one since this study investigated core composition studies articles and full-length books but not other forms of research (e.g., theses 
and dissertations). Our hope, therefore, is that other researchers will endeavor to replicate these methods with these other texts, both in composition studies as well as in other fields. In line with this, we have written this article in such a way to encourage such explorations (i.e., with a detailed literature review, methodology, and results).

\section{Acknowledgments}

We would like to thank Resa Bizzaro and Mike Williamson for being a constant inspiration in the area of composition studies; Jean Niencamp for her liberating thoughts on research methodology; and Jesse Winter for his editorial contributions. We would also like to thank the editors of the Journal for their suggestions and guidance.

\section{References}

Baker, J. R. (2020). Going Beyond Readability Formula: How do titles contribute to the readability of essays? International Journal of TESOL Studies, 2(1) 119-132 https://doi.org/10.46451/ijts.2020.06.o8

Berlin, J. (1987). Rhetoric and reality: writing instruction in American colleges, 1900-1985. Southern Illinois University Press.

Brannen, J. (Ed.). (2017). Mixing methods: Qualitative and quantitative research. Routledge

Carroll, L. 1872. Through the looking glass and what Alice found there. Henry Altemus Company.

Chu, H. (2015). Research methods in library and information science: A content analysis. Library $\mathcal{E}$ information science research, 37(1), 36-41. https://doi.org/10.1016/j.lisr.2014.09.003

Chu, H., \& Ke, Q. (2017). Research methods: What's in the name? Library $\mathcal{E}$ Information Science Research, 39(4), 284-294. https://doi.org/10.1016/j.lisr.2017.11.001

Creswell, J. W., \& Clark, V. L. P. (2017). Designing and conducting mixed methods research. Sage publications.

Donoghue, D. (2008). The last professors: The corporate university and the fate of the humanities. Fordham University Press.

Ede, L. S., \& Lunsford, A. A. (1990). Singular texts/plural authors: Perspectives on collaborative writing. Southern Illinois University Press.

Elbow, P. (1998). Writing without teachers. Oxford University Press.

Fraenkel, J.R, Wallen, NE, \& Hyun, H. (2011). How to design and evaluate research in education. McGrawHill.

Gee, J. P. (2007). Good video games + good learning: collected essays on video games, learning, and literacy. Lang.

Geertz, C. (1973). Thick description: toward an interpretive theory of culture, the interpretation of cultures: selected essays. Basic Books.

Ghiara, V. (2020). Disambiguating the role of paradigms in mixed methods research. Journal of Mixed Methods Research, 14(1), 11-25. https://doi.org/10.1177/1558689818819928

Given, L. M. (2008). The SAGE encyclopedia of qualitative research methods. Sage Publications 
Caruth, G. D. (2013). Demystifying mixed methods research design: A review of the literature. Online Submission, 3(2), 112-122. https://eric.ed.gov/?id=ED544121

Johnson, R. B., Onwuegbuzie, A. J., \& Turner, L. A. (2007). Toward a definition of mixed methods research. Journal of mixed methods research, 1(2), 112-133. https://doi.org/10.1177/1558689806298224

Lens, W. (1987). Theoretical research should be useful and used. International Journal of Psychology, 22(4), 453-461. doi:10.108o/00207598708246787

Lund, T. (2012). Combining qualitative and quantitative approaches: Some arguments for mixed methods research. Scandinavian Journal of Educational Research, 56(2), 155- 165. doi:10.108o/o0313831.2011.568674

Martin, W. E., \& Bridgmon, K. D. (2012). Quantitative and statistical research methods: From hypothesis to results (Vol. 42). John Wiley \& Sons.

Miles M. B., Huberman A. M. (1984). Qualitative data analysis: A sourcebook of new methods. Sage Publications.

Miller, S. (1992). Writing theory: Theory writing. In G. Kirsch, \& P. A. Sullivan (Eds.). Methods and methodology in composition research (pp. 15-36). Southern Illinois University Press.

Mutnick, D. (1998). Rethinking the personal narrative: life-writing and composition pedagogy. In C. Farris, \& C. M. Anson (Eds). Under construction: working at the intersections of composition theory, research, and practice (pp. 79-92). Utah State University Press.

Peckham, I. (2010). Going north thinking west: The intersections of social class, critical thinking, and politicized writing instruction. Utah State University Press.

Peritz, B. C. (1977). Research in library science as reflected in the core journals of the profession: A quantitative analysis (1950-1975). (Unpublished doctoral dissertation). University of California.

Ponterotto, J. G. (2006). Brief note on the origins, evolution, and meaning of the qualitative research concept thick description. The Qualitative Report, 11(3), 538-549.

https://nsuworks.nova.edu/tqr/volı/iss3/6

Ray, R. (1992). Composition from the teacher-research point of view. In G. Kirsch, \& P. A. Sullivan (Eds.) Methods and methodology in composition research (pp. 172-189). Southern Illinois University Press.

Sherman, L. A. (1893). Analytics of literature, a manual for the objective study of English prose and poetry. Ginn.

Silverman, D. (2016). Qualitative research. Sage Publications.

Strube, M. J. (2000). Reliability and generalizability theory. In L. G. Grimm \& P. R. Yarnold (Eds.), Reading and understanding MORE multivariate statistics (p. 23-66). American Psychological Association.

Sullivan, P. A. (1992) Feminism and methodology in composition studies. In G. Kirsch, \& P. A. Sullivan. (Eds.) Methods and methodology in composition research (pp. 15-36). Carbondale, IL: Southern Illinois University Press.

Thyer, B. (2010). Theoretical research. In Thyer, B. The handbook of social work research methods (pp. 468492). Sage Publications doi: 10.4135/9781544364902

Vandenberg, P. (1998). Composing composition studies: scholarly publication and the practice of discipline. In C. Farris, \& C. M. Anson (Eds). Under construction: working at the intersections of composition theory, research, and practice (pp. 19-29). Utah State University Press.

Vogt, W. P. (2008). Quantitative versus qualitative is a distraction: Variations on a theme by Brewer and Hunter (2006). Methodological Innovations Online, 3(1), 18-24. https://doi.org/10.4256/mio.2008.0007

White, C., Woodfield, K., \& Ritchie, J. (2003). Qualitative research practice: A guide for social science students and researchers. Sage Publications. 
Zebroski, J. (1998). Toward a theory of theory for composition studies. In C. Farris, \& C. M. Anson (Eds). Under construction: working at the intersections of composition theory, research, and practice (pp. 3050). Utah State University Press.

John R. Baker has worked with writing and self-access centers and taught writing, ESOL, and literature courses in the United States, and Asia (Korea, Taiwan, and Vietnam. His research interests include second-language reading and writing, self-access and writing center administration, various literature interests, research methods, and how these come together in an interdisciplinary nature. Email: drjohnbaker@yahoo.com

Patrick Bizzaro has published eleven books of poetry, most recently Against Confusion from Mount Olive College Press and Interruptions from Finishing Line Press. To Bizzaro's credit are two critical studies of Fred Chappell's poetry and fiction with LSU Press, a book on the pedagogy of academic creative writing with NCTE, four textbooks, and a couple hundred poems, reviews and review essays in literary magazines. His articles on Creative Writing Studies and composition have appeared regularly in College English and College Composition and Communication. He has won the Madeline Sadin Award from NYQ and Four Quarter's Poetry Prize as well as a Fulbright to visit South Africa during 2012. Bizzaro, first Director of the University Writing Program at East Carolina University in Greenville, NC, is a UNC Board of Governor's Distinguished Professor for Teaching and ECU Scholar-Teacher Award winner. His co-edited book on poet and pedagogue Wendy Bishop, Composing Ourselves as Writer-Teacher-Writers, was published spring 2011 by Hampton Press. Email: pbpp@auxmail.iup.edu. 